OPEN ACCESS

Edited by:

Nyuk Hien Wong,

National University of Singapore,

Singapore

Reviewed by:

Dimitrios Kraniotis,

OsloMet-Oslo Metropolitan University,

Norway

Ali Behnood,

Purdue University, United States

${ }^{*}$ Correspondence:

Yusuf Cagatay Ersan

yusuf.ersan@agu.edu.tr

Specialty section:

This article was submitted to

Sustainable Design and Construction,

a section of the journal

Frontiers in Built Environment

Received: 04 June 2018 Accepted: 07 November 2018

Published: 23 November 2018

Citation:

Ersan YC, Palin D, Yengec

Tasdemir SB, Tasdemir K, Jonkers HM, Boon N and De Belie N (2018) Volume Fraction, Thickness, and Permeability of the Sealing Layer

in Microbial Self-Healing Concrete Containing Biogranules.

Front. Built Environ. 4:70.

doi: 10.3389/fbuil.2018.00070

\section{Volume Fraction, Thickness, and Permeability of the Sealing Layer in Microbial Self-Healing Concrete Containing Biogranules}

\author{
Yusuf Cagatay Ersan 1,2,3*, Damian Palin ${ }^{4,5}$, Sena Busra Yengec Tasdemir ${ }^{6}$, \\ Kasim Tasdemir ${ }^{6}$, Henk M. Jonkers ${ }^{4}$, Nico Boon ${ }^{2}$ and Nele De Belie ${ }^{3}$
}

${ }^{1}$ Department of Civil Engineering, Abdullah Gul University, Kayseri, Turkey, ${ }^{2}$ Department of Biochemical and Microbial Technology, Centre for Microbial Ecology and Technology (CMET), Ghent University, Ghent, Belgium, ${ }^{3}$ Magnel Laboratory for Concrete Research, Department of Structural Engineering, Ghent University, Ghent, Belgium, ${ }^{4}$ Section of Materials and Environment, Department of Materials, Mechanics, Management \& Design, (3Md), Delft University of Technology, Delft, Netherlands, ${ }^{5}$ Department of Materials Science and Engineering, Cornell University, Ithaca, NY, United States, ${ }^{6}$ Department of Computer Engineering, Abdullah Gul University, Kayseri, Turkey

Autonomous repair systems in construction materials have become a promising alternative to current unsustainable and labor-intensive maintenance methods. Biomineralization is a popular route that has been applied to enhance the self-healing capacity of concrete. Various axenic microbial cultures were coupled with protective carriers, and their combination appears to be useful for the development of healing agents for realizing self-healing concrete. The advantageous traits of non-axenic cultures, such as economic feasibility, self-protection, and high specific activity have been neglected so far, and thus the number of studies investigating their performance as healing agents is scarce. Here we present the self-healing performance of a mortar containing a healing agent consisting of non-axenic biogranules with a denitrifying core. Mortar specimens with a defined crack width of $400 \mu \mathrm{m}$ were used in the experiments and treated with tap water for 28 days. Self-healing was quantified in terms of the crack volume reduction, the thickness of the sealing layer along the crack depth and water permeability under 0.1 bar pressure. Complete visual crack closure was achieved in the bio-based specimens in 28 days, the thickness of the calcite layer was recorded as $10 \mathrm{~mm}$ and the healed crack volume was detected as $6 \%$. Upon self-sealing of the specimens, the water permeability decreased by $83 \%$. Overall, non-axenic biogranules with a denitrifying core shows great potential for development of self-healing bioconcrete.

Keywords: microbial self-healing, bacteria-based concrete, concrete permeability, X-ray computed tomography, carbonate precipitation, nitrate reduction, self-protected culture

\section{INTRODUCTION}

The manual monitoring and repair of cracks in reinforced cementitious structures are important to increase their durability. An alternative approach is to use a cementitious composite which is able to repair itself when damaged. The latter is a greener approach as it significantly increases the service life of the structure up to 94 years and thus decreases the overall carbon footprint of the 
structure (Silva, 2015; Van Belleghem et al., 2017). Accordingly, considerable effort has been made by researchers to develop a self-healing concrete.

One of the most promising approaches for the development of self-healing concrete employs microorganisms. The healing mechanism of this bioconcrete takes advantage of microbial induced calcium carbonate precipitation (MICP). For this approach, metabolic pathways, such as aerobic respiration (Wiktor and Jonkers, 2011; Tziviloglou et al., 2016; Palin et al., 2017; Alazhari et al., 2018), urea hydrolysis (Wang et al., 2014a; Silva et al., 2015b) and biogenic nitrate reduction (Erşan et al., 2015a, 2016a) have been proposed by several researchers. The use of metabolism specific bacteria in concrete has resulted in predictable and reproducible crack healing.

Axenic microbial cultures (Bacillus sphaericus, Bacillus cohnii, Bacillus halmapalus, Bacillus pseudofirmus, Diaphorobacter nitroreducens) immobilized on various porous carriers (i.e., hydrogels, expanded clay, granular activated carbon, expanded perlite, various alginate beads) or in microcapsules were assessed thoroughly; and several combinations were already suggested for further testing at higher scales (Wiktor and Jonkers, 2011; Wang et al., 2014a,b; Erşan et al., 2016a; Palin et al., 2017; Zhang et al., 2017). Yet, as the production of suggested axenic cultures requires strictly controlled aseptic conditions at large scales, the product cost of self-healing bioconcrete reaches as high as 2,400 EUR $/ \mathrm{m}^{3}$ (Silva, 2015; Silva et al., 2015a). Such high costs brought up economic concerns related to the application of the technology in situ.

In order to overcome the economic issues, the use of specific non-axenic microbial cultures as healing agents were proposed in a few studies (Erşan et al., 2015a; Silva et al., 2015b). Less complicated production procedure compared to axenic cultures and self-protection capability that avoids the need for protective carriers were emphasized as the main advantages of the proposed non-axenic cultures (Erşan et al., 2015a; Silva et al., 2015b). Accordingly, the overall cost of the self-healing bioconcrete developed by using non-axenic cultures was reported to be 10 to 20 times lower than the ones developed by using axenic cultures (Erşan et al., 2015a; Silva et al., 2015a,b). One of these special non-axenic cultures, so called, active compact denitrifying core (ACDC) was achieved through granulation of nitrate reducing bacteria (Erşan et al., 2015a). Previous tests of ACDC granules as healing agents revealed that they are compatible with concrete, can survive in mortar and induce complete crack closure up to $500 \mu \mathrm{m}$ crack width in 28 days (Erşan et al., 2015a,b; Erşan et al., 2016b). Some qualitative evidence of the healing product from the deeper layers of the crack was also presented (Erşan et al., 2015a), yet the quantitative information related to the scale of the sealing layer and the healed crack volume is still unknown.

Identification of the scale of the mineral layer is of significance to clarify whether the crack closure is at the crack mouth or it happens all along the crack depth and has potential to contribute to the strength regain of the material. Currently, the amount of studies presenting the thickness of the sealing layer and the volume ratio of the healing products to the crack volume is limited. X-ray computed microtomography $(\mu \mathrm{CT})$ is a promising tool to evaluate the extent of healing along the crack depth and so far, to our knowledge, there is only one study which used such approach for quantification of the bacteriabased self-healing. In their study, Wang et al. (2014a) reported that the healing products intensely occurred at the top $1 \mathrm{~mm}$ of the crack depth, which makes sense considering the oxygen requirement of aerobic ureolytic bacteria. We hypothesize that the thickness of the sealing layer can proceed further toward the crack depth, since ACDC follows an oxygen independent nitrate reduction pathway for MICP (Erşan et al., 2015a). Applying non-destructive X-ray computed microtomography for the evaluation of the sealing layer in ACDC containing bioconcrete can unveil the aforementioned missing performance parameter. Therefore, the first objective of this study is to quantify the scale of the sealing layer and the healed crack volume in $\mathrm{ACDC}$ containing bioconcrete following the successful self-healing of a crack.

The main reason for developing self-healing concrete is to protect the steel reinforcement bars inside the reinforced concrete from exposure to the outer environment and thus increase the durability. Therefore, water tightness regain is essential for successful self-healing. Unfortunately, $\mu \mathrm{CT}$ scanning and image analyses are limited for adequate evaluation of the fate of the sealing layer and the water tightness under certain water head. A water permeability test described by Palin et al. (2018) can be useful to quantify water tightness regain of mortar upon bacteria-based self-healing. Compared to conventional water permeability test setups, this new method offers rapid (i.e., $10 \mathrm{~h}$ for 21 specimens), accurate and reproducible permeability data for a defined crack width, since spacers are used to split cylinders and create reproducible crack dimensions (i.e., crack widths with $20 \mu \mathrm{m}$ deviation from the desired crack width). The method was previously used to quantify the water tightness regain of a bacteria-based selfhealing cementitious composite designed for low-temperature marine environment (Palin et al., 2017). Since the setup is particularly relevant for quantifying water tightness regain, it is also applicable for fresh water conditions. Therefore, the second objective of this study is to quantify the permeability of ACDC containing bioconcrete following the successful self-healing of a crack.

The overall objective of the study is to enhance the available quantitative information about the self-healing performance of ACDC containing self-healing concrete and introduce nonaxenic biogranules as a promising contender to other proposed healing agents.

\section{MATERIALS AND METHODS \\ Bacterial Granules}

ACDC granules were cultivated in a sequencing batch reactor by following the operational conditions and the procedure previously described by Erşan et al. (2015a). Obtained granules were dried at $60^{\circ} \mathrm{C}$ for $48 \mathrm{~h}$ in a drying tunnel with ventilation. Dry powders were stored in closed containers at room temperature until incorporation into the mortar specimens. 


\section{Preparation of Mortar Specimens}

Mortar specimens were preferred to conduct the experiments at laboratory scale since testing biomortar at laboratory scale required smaller amount of materials, ACDC granules in particular, and experimentation costs were lower when compared to testing bioconcrete specimens. In total two plain control series (P1 and P2), one abiotic control series and one biomortar series containing ACDC were prepared. The first plain control series (P1) was useful to assess the autogenous healing performance. The second plain control series (P2) was used to quantify the initial water permeability through a certain crack width (details are given in Section Water Permeability). Abiotic control series was included in the tests to reveal any deviation in the autogenous healing performance of mortar due to the nutrient admixtures which are necessary for bacteria. Biomortar series was the actual test series that bacteria-based healing was quantified and evaluated.

Cylinder mortar specimens with $60 \mathrm{~mm}$ height and $33.5 \mathrm{~mm}$ diameter were cast by using sand, CEM I $42.5 \mathrm{~N}$ cement and tap water with the mass ratio of 3:1:0.5, according to $\mathrm{EN}$ 1015-11. Abiotic control series contained only the nutrient admixtures (2\% w Ca-formate/w cement and 3\% w Ca-nitrate/w cement) used for bacteria in addition to the plain mortar ingredients. Admixtures were added into the mortar mix in the powder form during the mixing process. For biomortars, in addition to the plain mortar ingredients and the nutrients, ACDC granules were added into the mixture in the powder form with a $0.5-2 \mathrm{~mm}$ particle size $(2.25 \mathrm{~g}$ bacteria or $3.20 \mathrm{~g}$ ACDC, i.e., $0.5 \%$ bacteria $\mathrm{w} / \mathrm{w}$ cement,) during the mixing process. No protective carriers were used while incorporating the bacteria as ACDC is a self-protected culture (Erşan et al., 2015a, 2016b).

Silicon molds were designed to have two diametrically opposite notches ( $2 \mathrm{~mm}$ wide and $3 \mathrm{~mm}$ deep) on the cast mortar specimens, all the way running down their side (Figure 1A). Each series had 10 specimens, and they were cured for 28 days at room temperature inside a tightly sealed polyethylene bag prior to crack formation.

\section{Cracking of the Specimens and Treatment for Healing}

After 28 days of curing, specimens were split under compressive load. Steel rods were used to support the symmetrical notches during diametrical compression over symmetrical points. Compressive loading was applied on the steel rods, placed at the notches, at $0.01 \mathrm{~m} \cdot \mathrm{s}^{-1}$ until the specimens diametrically split along the notches (Figure 1B).

The specimens were completely split and any fine particles present on the inner surface of the specimens produced during cracking were removed by gently blowing the inner surface of the specimens. Metal spacers of $2.4 \mathrm{~mm}$ wide were placed between the notches, and the split halves were glued to achieve defined cracks of $400 \mu \mathrm{m}$ wide (Figure 1C). A mixture of Plex 7742 and liquid Pleximon 801 (Evonik Röhm GmbH, Darmstadt, Germany) was used to glue the halves of the specimens along the notches.
Specimens with $\sim 400 \mu \mathrm{m}$ wide crack were used for crack closure monitoring, $\mu \mathrm{CT}$ analysis and water permeability tests. The average crack width and the standard deviation obtained for 10 specimens of each series are given in Table 1.

One of the plain control series (plain control-1, P1) was used to determine the autogenous healing potential and exposed to identical conditions as the abiotic control, and ACDC series. The second plain control series (plain control2, P2) was used only during water permeability analysis to quantify the water flow through the $400 \mu \mathrm{m}$ crack before healing.

After cracking, the initial $\mu \mathrm{CT}$ analysis was conducted on plain control-1, abiotic control and ACDC series. Following $\mu \mathrm{CT}$ analysis, the series were immersed in tap water for 28 days. During the immersion, the water depth inside the buckets was $\sim 100 \mathrm{~mm}$.

\section{Quantification of Self-Healing Properties Crack Closure}

Crack closure was monitored biweekly through stereomicroscope with apochromatic optics (Leica S8 Apo). Obtained images were further analyzed for the decrease in crack width by using image analysis software (The Leica Application Suite, LAS 2.8). Crack closure efficiency was calculated by using Equation (1);

$$
\text { Crack closure } \%=\left[1-\left(\mathrm{w}_{\mathrm{t}} / \mathrm{w}_{\text {initial }}\right)\right] \times 100
$$

where;

$\mathrm{w}_{\mathrm{t}}=$ crack width measured at a certain time $\mathrm{t}(\mathrm{d})$

$\mathrm{w}_{\text {initial }}=$ initial crack width

The crack closure performance of each series was quantified biweekly through 60 data points collected along the cracks of 10 separate specimens. Statistical analyses were conducted to compare significant differences by means of one way ANOVA test $(p=0.05)$.

\section{Water Permeability}

The rapid water permeability test setup described by Palin et al. (2018) was used for quantification. The method allows accurate quantification of permeability of cracked specimen with a defined crack width since reproducible crack dimensions were achieved by applying spacers as described in Section Cracking of the Specimens and Treatment for Healing. In total five permeability columns were set up to run in parallel. The water level in each column was $100-105 \mathrm{~cm}$ resulting in 0.1 bar water head. The water head was kept as steady as possible throughout the experiment by gently adding water to the top container. In total 10 cracked specimens were tested from each series. Fresh tap water was poured into containers connected to the upper side of each permeability column. The cracked specimens were placed at the bottom end of the column by using holders and gaskets as described in Palin et al. (2018). Container outlets were controlled with screwed caps and water was released at the same time for each column initiating the water permeability test. A digital stopwatch was used to track the time elapsed during the permeability test. Separate catchment buckets were used to collect the water 
A

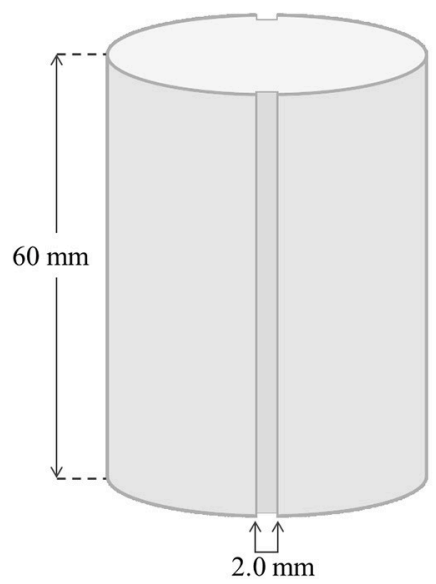

Step 1

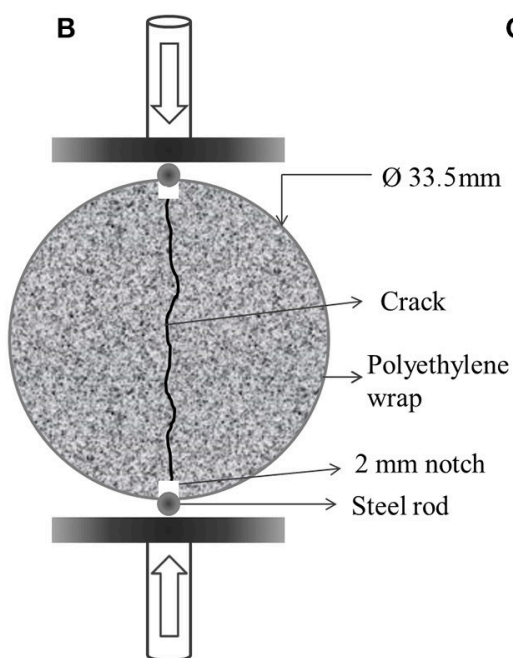

Step 2

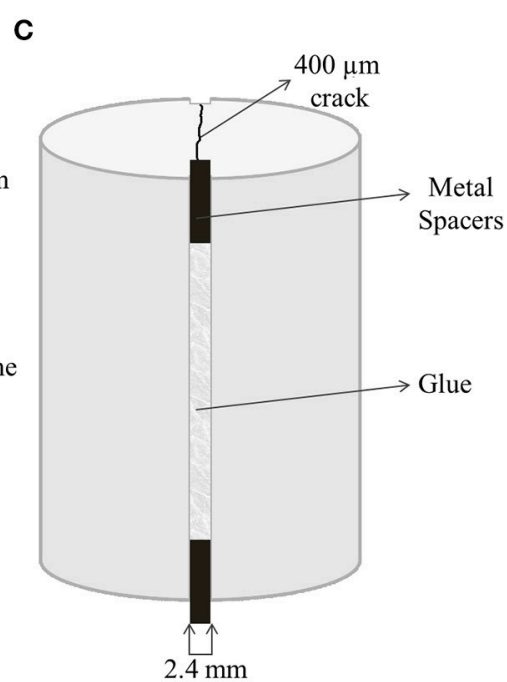

Step 3

FIGURE 1 | Preparation procedure of the uniform mortar specimens for quantification of self-healing. Dimensions of the cast cylinder specimens with diametrically opposite notches (A); complete splitting of the mortar specimen along the notches by means of Brazilian splitting setup (B); creation of a reproducible $400 \mu \mathrm{m}$ wide crack by gluing the $2.4 \mathrm{~mm}$ wide metal spacers into $2 \mathrm{~mm}$ notches (C).

TABLE 1 | The number of specimens and their respective average crack widths regarding to each test set-up.

\begin{tabular}{|c|c|c|c|c|}
\hline \multirow[t]{3}{*}{ Series } & \multicolumn{4}{|c|}{ Tests } \\
\hline & \multicolumn{2}{|c|}{ Permeability $^{a}$} & \multicolumn{2}{|c|}{$\mu \mathrm{CT}$} \\
\hline & Number of specimens & $\begin{array}{l}\text { Initial average crack } \\
\text { width }(\mu \mathrm{m})\end{array}$ & Number of specimens & $\begin{array}{c}\text { Initial average crack } \\
\text { width }(\mu \mathrm{m})\end{array}$ \\
\hline Plain control 1 & 10 & $404 \pm 41$ & 3 & $400 \pm 11$ \\
\hline Plain control 2 & 10 & $408 \pm 31$ & $\mathrm{~N} / \mathrm{A}^{b}$ & $\mathrm{~N} / \mathrm{A}$ \\
\hline Abiotic control & 10 & $409 \pm 28$ & 3 & $397 \pm 5$ \\
\hline $\begin{array}{l}\text { Biomortar with } \\
0.5 \% \text { ACDC }^{C}\end{array}$ & 10 & $399 \pm 27$ & 3 & $398 \pm 4$ \\
\hline
\end{tabular}

aPermeability of "Plain control 2" was only tested before and the others were tested only after the 28 days healing period. ${ }^{b} \mathrm{~N} / \mathrm{A}$, not applicable. ${ }^{\mathrm{C}} \mathrm{ACDC}$, non-axenic nitrate reducing biogranules so called "Activated Compact Denitrfiying Core."

flowing through each crack. The weight of the collected water was recorded at the end of 5, 10, and $30 \mathrm{~min}$ of water flow. The procedure was repeated until all the specimens from each series were tested. The room temperature was recorded as $20^{\circ} \mathrm{C}$.

Since the water flowing through the crack washes out compounds for healing (fine particles, healing agent and $\mathrm{OH}^{-}$ ions) and influences the $\mathrm{pH}$, an initial permeability test was not conducted for the treated specimens prior to healing treatment. Instead, a batch of 10 cracked plain control specimens, named $\mathrm{P} 2$, were used to determine the initial flow through $400 \mu \mathrm{m}$ crack width. P1, abiotic control and ACDC batches were tested only after a 28 days healing period. The water permeability $(\mathrm{m} / \mathrm{s})$ of healed batches were compared among each other and with the initial values obtained for the P2 batch. Statistical significance of the variations was determined by means of one way ANOVA test $(p=0.05)$.

\section{X-ray Computed Tomography (3D Analysis of the Crack Sealing)}

$\mathrm{X}$-ray computed microtomography $(\mu \mathrm{CT})$ was used to monitor crack healing along the crack depth. From each series, three specimens were selected for the analysis. Selected specimens were scanned immediately after cracking and after 28 days treatment with tap water. Prior to scanning of the specimens treated with tap water for 28 days, specimens were dried for $48 \mathrm{~h}$ at $40^{\circ} \mathrm{C}$. A volume of $28.2 \mathrm{~cm}^{3}$ (32 mm height) of a $52.8 \mathrm{~cm}^{3}$ ( $60 \mathrm{~mm}$ height) specimen was scanned, to keep the resolution as high as possible (voxel size of $16.6 \mu \mathrm{m}$ ). The scan resulted in 1,440 images for a complete $360^{\circ}$ rotation (an image per $0.25^{\circ}$ rotation). A $200 \mu \mathrm{m}$ thick copper filter was used to minimize the interference of the beam hardening. The raw images were further reconstructed by using VG Studio Max 2.0. Following reconstruction, front and top view image stacks were extracted in DICOM format for further image analyses. The effective crack width along the 
specimen height and the volume fraction of the sealing materials (i.e., microbially induced $\mathrm{CaCO}_{3}$ precipitates) with respect to the crack volume were quantified via image analyses. Furthermore, the spatial distribution of the sealing materials was determined.

\section{Image Analyses}

Image processing tools were used to accurately quantify the MICP that occurred along the crack depth and its volume ratio to the crack volume. The methods used in this section were implemented using Matlab software. First 150 slices from the top surface and 250 slices from the bottom were discarded since the color distribution, sharpness, distribution of illumination, distortion and noise of those slices was not similar to the other images. Therefore, image analyses were applied only for $30.3 \mathrm{~mm}$ $\left(27 \mathrm{~cm}^{3}\right)$ of the specimen.

Preliminary visual inspection of the reconstructed images revealed that microbially induced calcite precipitates did not have a distinct intensity for extraction. Therefore, instead of simple thresholding segmentation, it was decided to extract the crack zone and analyse it for empty and healed regions which would give an accurate healing percentage with respect to the crack volume.

Firstly, the mortar matrix was eliminated using thresholding. In order to segment out the mortar region, Otsu's thresholding method was used. After thresholding, the crack, MICP, glue, and porosity were left. In order to avoid discontinuation of the crack at points where crack got too narrow, Otsu's threshold value was scaled down by 0.9. Afterward, all mask layers of a single mortar sample were combined to construct a 3D model. In the 3D model, pores and the total crack appeared. A connected component analysis was performed by using 18 pixel connectivity, to remove porosity from the $3 \mathrm{D}$ model. Since the largest connected component was the crack, the crack region could be extracted and the porosity could be eliminated. The porosity connected to the crack zone was included in further analyses.

The extracted crack zone was further skeletonized and the crack pattern between the notches was determined with a line. The spurs appearing during the skeletonizing were eliminated by selection of the shortest path from the beginning to the end of the skeleton. The pixel size of the line was expanded to cover the pixels in the crack area, hence an area of interest following the same pattern with the crack was obtained. The pixel values under the obtained area were analyzed to quantify the healing material, MICP, inside the crack. Pixels containing glue, empty crack, and MICP showed distinctive intensities. Multiple thresholding was applied to extract the region where MICP was present. High and low threshold values were set empirically. The resulting binary image showed a considerable amount of noise outside the MICP region. Since the MICP region had the highest true pixel density in the binary image, it could be extracted by segmenting the region with the highest true pixel density inside the mix. Accordingly, a Gaussian low-pass filter was applied to make the MICP region brighter than the other parts of the image. Then, an additional thresholding was applied which resulted in another binary image of the segmented MICP region. A morphological closing operation was applied to connect broken MICP regions due to a small intensity difference. Finally, the overall region was used for segmentation of the MICP and the empty zone.

When the pixel values were normalized between $[0,1]$, empirical observations showed that pixel values above 0.3 belonged to glue. Therefore, those pixels were discarded. The pixel values of the MICP region mostly fell into [0.15-0.3] range, and the values of empty region pixels were below 0.15 . Using those thresholds empty regions and healed regions were separated. A further application of 1D morphological closing followed by opening resulted in the elimination of possible noise. Such elimination connected the gaps between the empty regions and the gaps between MICP regions. Obtained values were used to calculate the ratio of the healed volume to the total crack volume by using Equation (2):

$$
\text { Healed volume } \%=\left[\mathrm{V}_{\mathrm{H}} /\left(\mathrm{V}_{\mathrm{H}}+\mathrm{V}_{\mathrm{E}}\right)\right] \times 100
$$

where;

$\mathrm{V}_{\mathrm{H}}=$ number of voxels of MICP region

$\mathrm{V}_{\mathrm{E}}=$ number of voxels of empty region

The explained operations were applied to all analyzed series. For each series, mean values and standard deviations obtained from three samples were presented. Comparisons among different series were made by means of one way ANOVA test $(p=0.05)$.

\section{Identification of the Healing Material}

After all the tests were completed, healing material was scraped from the crack by using stainless steel spatula $(\sim 12 \mathrm{mg})$, and ground to fine powder. A portion of the ground powder $(<5 \mathrm{mg})$ was chemically characterized by using Fourier transform infrared (FTIR) spectroscopy. Presented spectra were the result of 32 scans with a resolution of $4 \mathrm{~cm}^{-1}$ in the range of $4,000-500 \mathrm{~cm}^{-1}$. Furthermore, healed biomortar specimens were split into two pieces, and the inner surfaces were coated with carbon $(20-30 \mathrm{~nm}$ thickness) and analyzed under Scanning Electron Microscope (SEM) coupled with Energy Dispersive X-ray Spectroscopy (EDS). The micrographs showing the inner crack surface of the healed specimens were taken at accelerating voltage of $15 \mathrm{kV}$ at a working distance of 8-9 $\mathrm{mm}$.

\section{RESULTS}

\section{Improved Crack Closure Performance by Biomortar}

Prepared mortar series with a $400 \mu \mathrm{m}$ wide crack and varying composition were treated with tap water for 28 days, and the crack closure performances were recorded biweekly. In the first 14 days of the tap water treatment, biomortar did not show any better crack closure performance than the control series. All series showed a crack closure performance between 10 and 30\% (Figure 2A). As seen in Figure 3, a relatively small amount of calcium carbonate was formed in the crack. 

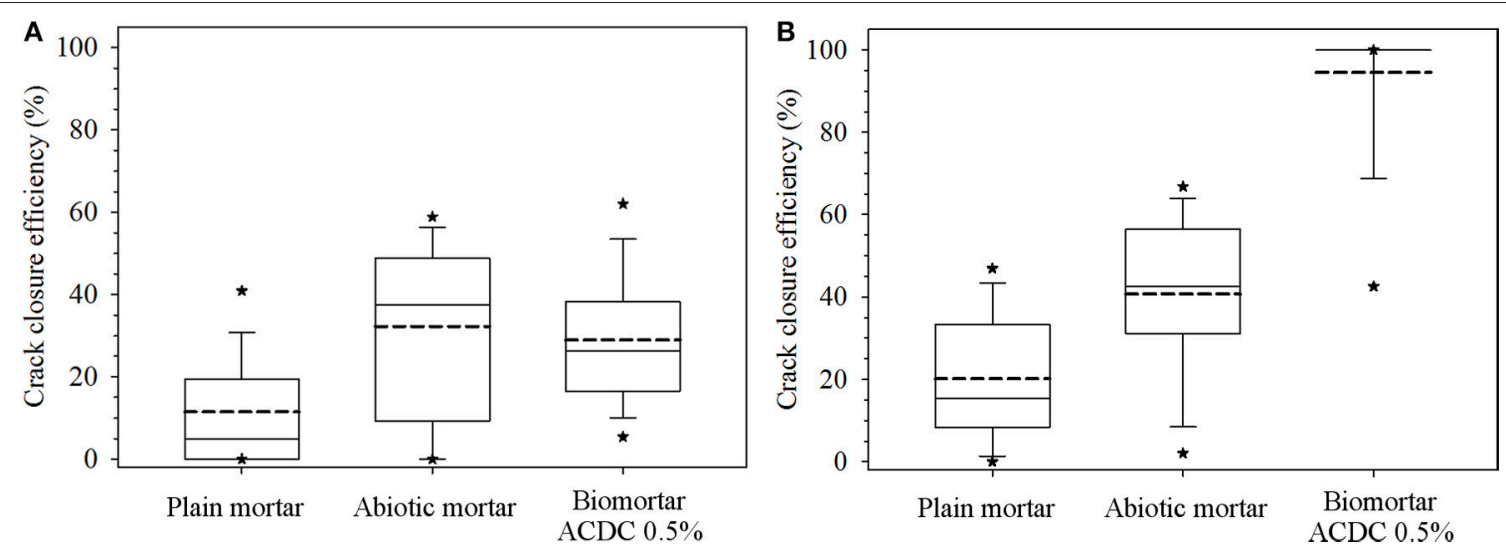

FIGURE 2 | Data depicting crack closure performances of different series obtained for the first 14 days (A) and at the end of 28 days (B). Each box plot represents the crack closure performance data for 60 data points collected along the cracks of 10 separate specimens. The dashed line represents the mean crack closure percentage; the top, middle and bottom lines are the 75, 50, and 25th percentiles, respectively. The whiskers shows the minimum and maximum crack closure. *Indicates 5th/95th percentiles.

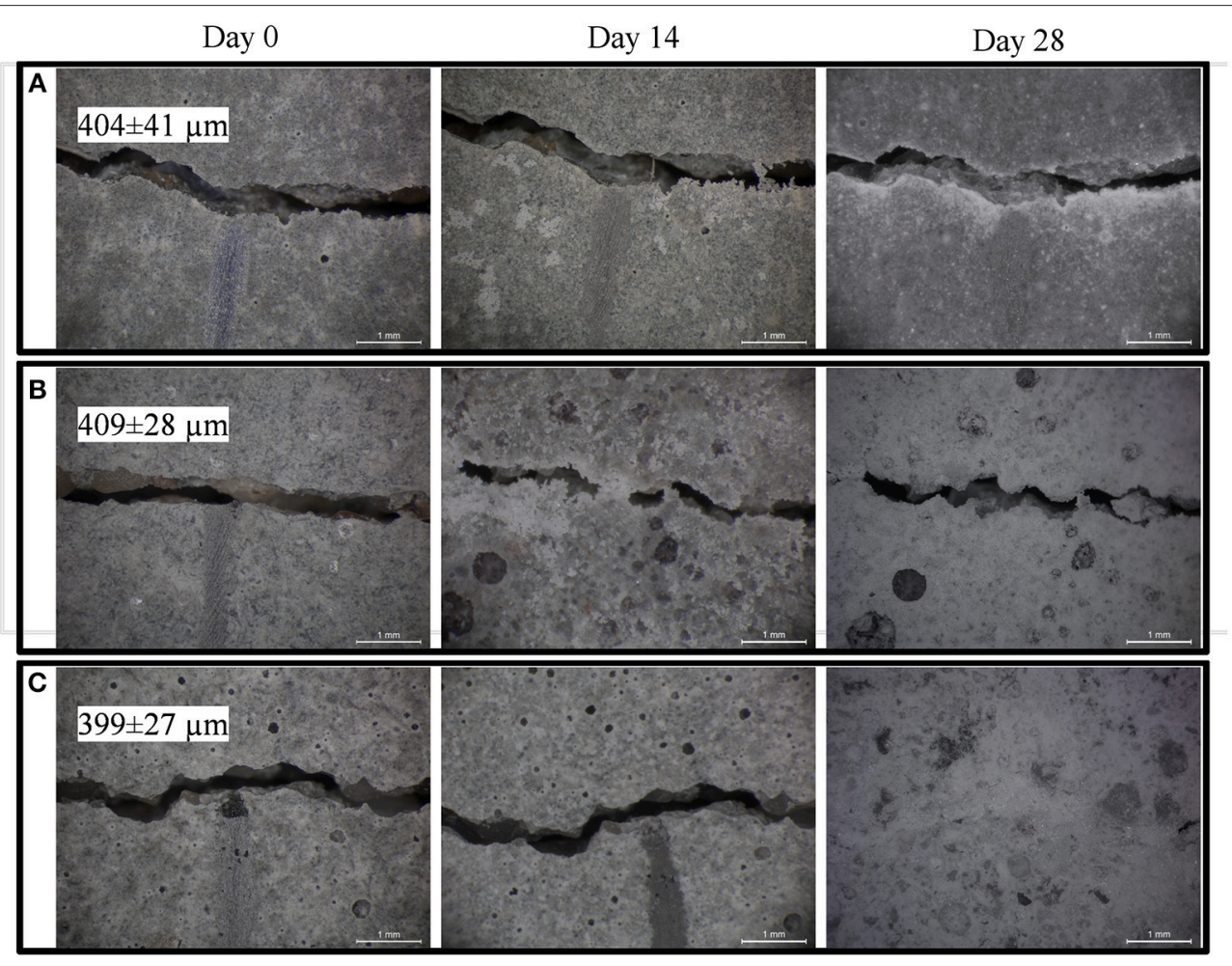

FIGURE 3 | Micrographs showing biweekly evolution of the crack at the specimen surface in plain control series (A); abiotic control series (B); biomortars containing ACDC biogranules (C). Crack widths are given as mean \pm standard deviation $(n=10)$.

At the end of the 28 days treatment, a significant difference ( $p=0.05$ ) was observed between the control series and ACDC containing biomortars. In biomortars, visual crack closure of a $400 \mu \mathrm{m}$ wide crack was noted as $95 \%$ while the cracks in plain control and abiotic control specimens closed by 20 and $40 \%$, respectively (Figure 2B). A significant amount of calcium carbonate was formed on the surface of the specimens and in the cracks (Figure 3).

\section{Decreased Water Permeability of Healed Biomortar}

The effects of both autogenous and microbial healing on the permeability of cracked mortar were quantified. The initial permeability value was determined by measuring the water flow through the specimens with a $\sim 400 \mu \mathrm{m}$ wide crack under a pressure head of $1.05 \mathrm{~m}$ ( 0.1 bar), in test durations of 5,10 , and $30 \mathrm{~min}$. The initial permeability of a mortar with a $408 \pm$ 


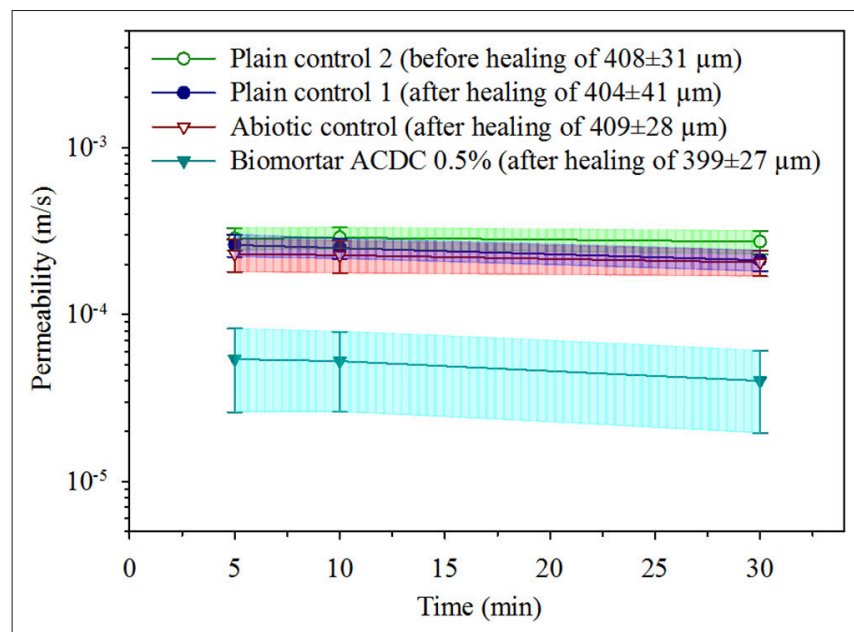

FIGURE 4 | The water permeability data obtained under 0.1 bar pressure for unhealed mortar, autogenously healed mortar and microbially healed biomortar. Given data are the mean and the error bars represent standard deviation $(n=10)$

$31 \mu \mathrm{m}$ wide crack was found to be $[29 \pm 5] \mathrm{E}-5 \mathrm{~m} / \mathrm{s}$ (Figure 4). Regardless of the series, no significant differences were observed between the permeability values obtained in 5, 10, and $30 \mathrm{~min}$ test durations. In both control series (plain control and abiotic control), 28 days treatment with tap water did not result in a significant change in permeability of the cracked mortar $(p=$ $0.05)$. In the plain control series, after 28 days autogenous healing of $404 \pm 41 \mu \mathrm{m}$ cracks, the permeability value was recorded as [24 \pm 4$] \mathrm{E}-5 \mathrm{~m} / \mathrm{s}$ (Figure 4). In abiotic control series, after autogenous healing of $409 \pm 28 \mu \mathrm{m}$ cracks for 28 days, the permeability value was recorded as $[22 \pm 5] \mathrm{E}-5 \mathrm{~m} / \mathrm{s}$ (Figure 4).

A substantial decrease in water permeability was achieved only in biomortars containing ACDC granules. After the microbial induced healing of $399 \pm 27 \mu \mathrm{m}$ cracks for 28 days, the permeability value was recorded as $[5 \pm 3] \mathrm{E}-5 \mathrm{~m} / \mathrm{s}$ which means $83 \%$ decrease in permeability when compared to the initial permeability of cracked mortar (Figure 4).

\section{Thick and Graded Mineral Layer of Healed Biomortars}

Tomography images revealed that a crack with a consistent crack width of $\sim 400 \mu \mathrm{m}$ which was free of debris could be achieved for all tested series (Figures 5, 6A). The effective sealing depth was determined by analyzing the images obtained via X-ray computed microtomography. Figure 5C shows the spatial distribution of healing material along the crack depth in biomortar. In control series, calcium carbonate was not detected at deeper parts of the crack (Figures 5A,B). Figure 5D shows the crack closure percentage of all scanned biomortars along the crack depth for the zone deeper than $2.5 \mathrm{~mm}$ from the surface. Since the color distribution of the first 150 images from the top surface were not appropriate for compiled image processing, the spatial distribution of MICP could be determined only for the zone deeper than $2.5 \mathrm{~mm}(150 \times 16.6 \mu \mathrm{m})$. It was found that crack healing continued along the crack for about $10 \mathrm{~mm}$. However, after a depth of $10 \mathrm{~mm}$, no significant calcite formation occurred. Although 100\% crack closure could not be achieved at deeper layers, crack closure percentages could go up to $65 \%$ at a depth of $6 \mathrm{~mm}$ from the surface (Figure 5D). Manual surveying of the first 150 images from the top surface revealed that some healed parts, particularly in biomortar specimens, was lost due to exclusion of those images. For instance, Figure 6B shows a complete crack closure obtained in a biomortar at a depth of $800 \mu \mathrm{m}$ from the surface which could not be included in quantification of either the healed volume or the thickness of the sealing layer. Nevertheless, considering the calcite formed at the surface (Figure 3C), at a depth of $800 \mu \mathrm{m}$ (Figure 6B) and in the zone between 2.5 and $10 \mathrm{~mm}$ from the surface (Figure 5D), it wouldn't be an overestimation to define the thickness of the sealing layer as $\sim 10 \mathrm{~mm}$.

The volume of the MICP formed during microbial induced healing of the crack corresponded to $5.80 \%$ of the total crack volume (Figure 6C). In plain control and abiotic control series, the materials formed inside the crack corresponded to only 0.04 and $0.10 \%$ of the total crack volume, respectively (Figure 6C). The accuracy of the image processing was determined as $\% 0.05$; therefore, the healed volume in plain mortar control was not reliable. The healing material inside the healed crack volume did not show a uniform distribution which caused fluctuations in crack closure percentage along the crack depth (Figures 5C,D).

\section{Calcium Carbonate Is the Main Healing Material in Biomortars}

SEM observations are combined with EDS and FTIR analyses to identify the products responsible for the crack closure. Calcium carbonate, in the form of calcite $\left(1415,875\right.$, and $\left.713 \mathrm{~cm}^{-1}\right)$ and aragonite $\left(696 \mathrm{~cm}^{-1}\right)$, was the major constituent of the healing material (Figure 7A). Some other components from the mortar matrix, such as calcium-silicate-hydrate (C-S-H) $(1,082$ $\left.\mathrm{cm}^{-1}\right)$ and Al-O-H bands $\left(796 \mathrm{~cm}^{-1}\right)$ were also detected in FTIR analysis (Figure 7A). Presence of similar compounds were confirmed by EDS peaks as well (Figure 7B).

A significant amount of microbial footprints were detected on the calcium carbonate precipitates (Figure 7C). Spherical footprints had a diameter of $\sim 5 \mu \mathrm{m}$. The length, width and depth of the rod-shaped footprints were $\sim 3, \sim 1.5$, and $\sim 1 \mu \mathrm{m}$, respectively. The former sizes were quite large to belong to one single bacterium. Detailed surveying of the spheres revealed that a cluster of bacteria were responsible for the observed large traces. Precipitated calcium carbonate formed around bacteria clusters and connected as the mineral grew (Figure 7C). Considering that a granulated microbial culture, which consists of massive clusters of bacteria, was used as a healing agent, it was possible that the observed clusters of bacteria were also connected beneath the precipitated minerals.

\section{DISCUSSION}

Crack closure performance in the first 14 days was between 10 and $30 \%$ for all tested series (Figure 2A) which meant that 

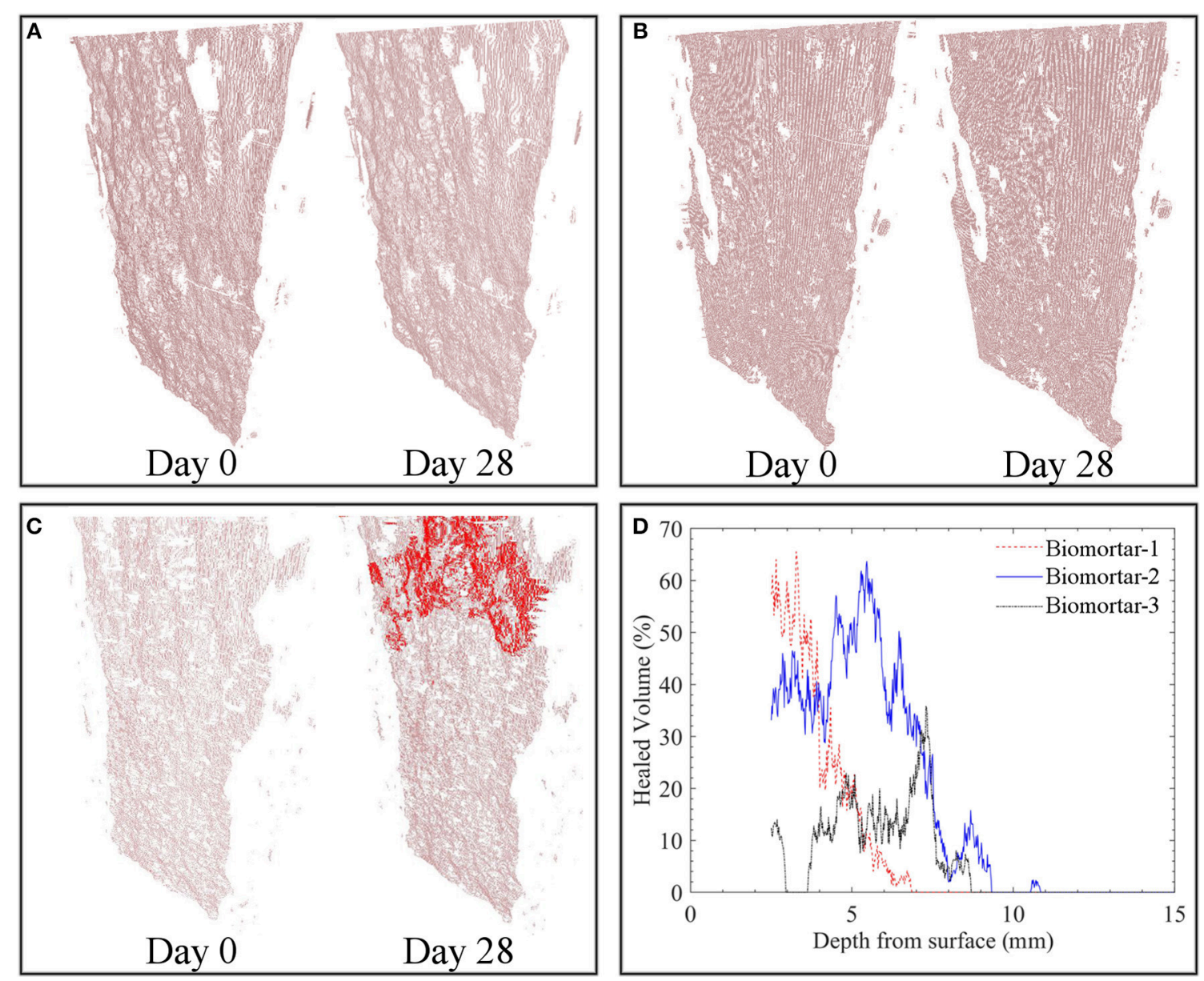

FIGURE 5 | Spatial distribution of the calcium carbonate inside the extracted crack volume before and after 28 days tap water treatment of plain control specimens (A); abiotic control specimens (B); biomortars (C) and the crack closure percentage at $16.6 \mu \mathrm{m}$ layered increments starting from the surface (D). Red zones represent MICP and pinkish zones represent the empty crack. For interpretation of the references to color in this figure legend, the reader is referred to the web version of this article.

significant $\mathrm{CaCO}_{3}$ precipitation was not observed in the first 14 days. Therefore, the healing in this period was attributed to other autogenous healing mechanisms, such as swelling of the crack walls and further hydration of non-hydrated dicalcium silicate $\left(\mathrm{C}_{2} \mathrm{~S}\right)$ particles (de Rooij et al., 2013). The results of this study revealed that, in the first 2 weeks, the response of the biomortar to the presence of a crack is no different than a conventional mortar. This idle period became reasonable when the total time required for significant $\mathrm{pH}$ drop and subsequent resuscitation period of biogranules were considered. As reported previously, resuscitation of ACDC granules took 1 week subsequent to the $\mathrm{pH}$ drop to around 10 (Erşan et al., 2016b). The healing performance of biomortar in the first 14 days was significant to provide information on the time period that the reinforcement bar would be exposed to the environmental conditions in real life. Since no significant healing was achieved in early stages of the treatment, it should be noted that biomortars with self-healing capability could not eliminate the risk of corrosion initiation of the embedded steel rebar in early stages of the crack healing.
The autogenous healing limits of the control specimens were determined as $\sim 80$ and $\sim 160 \mu \mathrm{m}$ for plain control and abiotic control specimens, respectively, following the 28-days treatment with tap water. Previous studies reported comparable results under similar incubation conditions (immersion in tap water; Wiktor and Jonkers, 2011; Stuckrath et al., 2014; Wang et al., 2014b; Silva et al., 2015b; Zhang et al., 2017). The better crack closure performance of the abiotic control specimens than the reference specimens was also consistent with the reported findings and could be attributed to the reported positive effect of admixtures on $\mathrm{CaCO}_{3}$ precipitation (Stuckrath et al., 2014; Wang et al., 2014b; Erşan et al., 2015a, 2016a; Silva et al., 2015b). The healing potential of biomortar was found to be enough to seal a $400 \mu \mathrm{m}$ crack following 28 days immersion in tap water. Observed crack closure performance of the biomortar was also consistent with the previously reported microbial self-healing results (Wang et al., 2014b; Erşan et al., 2015a; Silva et al., 2015b; Zhang et al., 2017). More importantly, the findings were consistent with the previous 

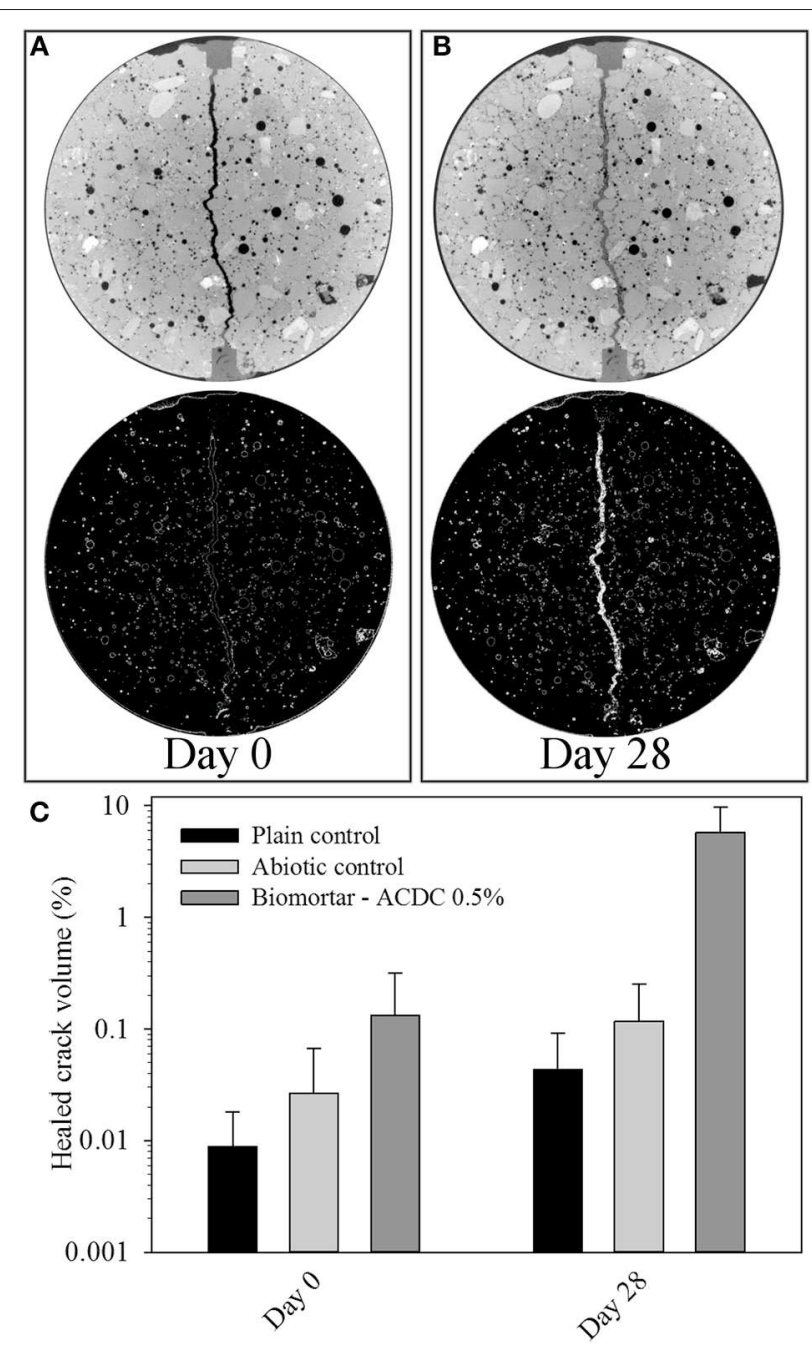

FIGURE 6 | Tomography images showing the state of the crack at a depth of $800 \mu \mathrm{m}$ immediately after cracking (A); after 28 days treatment (B); and the healed volume percentages with respect to the extracted 3D crack volume between 2.5 and $32.8 \mathrm{~mm}$ from the top surface (C). Color white in thresholded images represents materials having the same pixel value with calcium carbonate. Diameter of each micrograph is $33.5 \mathrm{~mm}$.

study where ACDC was used as a healing agent in biomortar (Erşan et al., 2015a). Hence the findings confirmed that the use of ACDC as a healing agent indeed provides a predictable and reproducible self-healing capacity for cementitious composites.

The results of this study were significant to understand the major differences between autogenous and microbial induced self-healing in terms of the spatial distribution of the healing materials and water tightness regain in these two mechanisms. On the one hand, in both of the control series, the $\mathrm{CaCO}_{3}$ precipitates forming due to autogenous healing were visualized at the crack mouth while no precipitation could be detected at the deeper zones of the crack. On the other hand, microbial induced crack healing occurred both at the surface, and it could continue as deep as $10 \mathrm{~mm}$ from the surface. This gradation in the thickness of the crack sealing material made it more resilient to damage under pressure and thus led to better water tightness regain in biomortar compared to conventional mortar (i.e., control specimens). Considering that 0.1 bar pressure was applied during the water permeability test, the applied pressure could damage the partial sealing occurred at the crack mouth during autogenous healing and cause loss of the healing material, which in turn prevented the water tightness regain in control specimens. However, for a thick sealing layer-like the ones occurred in biomortarsthe resilience against pressure was expected to be superior which led to the observed $80 \%$ difference in water permeability values of conventional mortar and biomortar after self-healing of a $400 \mu \mathrm{m}$ wide crack. Therefore, it can be claimed that biomortar could better isolate the reinforcement bar from the outer environment than the conventional cementitious composites.

The presented spatial distribution of $\mathrm{CaCO}_{3}$ precipitates was also significant to unveil the influence of the bacteria and their metabolic pathway on self-healing properties of biomortars. So far, the microbial induced healing (i.e., intense precipitation of $\mathrm{CaCO}_{3}$ ) of a concrete crack was observed at the first few millimeters from the top surface due to the limited availability of oxygen for the tested microbial healing agent (Wang et al., 2014a). However, the findings in this study revealed that bacterial activity and microbial induced self-healing inside the crack could occur at deeper zones of the crack when nitrate reducing ACDC culture was used as the healing agent instead of aerobic species. Complete crack closure could be visualized at a depth of $0.8 \mathrm{~mm}$ and healing products were detected at layers as deep as $10 \mathrm{~mm}$, since ACDC could oxidize organic carbon via nitrate respiration in the deeper layers of the crack where dissolved oxygen was not present (Erşan et al., 2015a, 2016b). The sealing layer in ACDC containing biomortar was almost 10 times thicker than the sealing layer in previously reported biomortars containing aerobic culture. This thicker sealing layer might lead to a more stable water tightness regain in ACDC containing biomortar than that in the aerobic bacteria-based biomortars, which should be noted for further investigation.

In microbially healed specimens, the healed volume in a $400 \mu \mathrm{m}$ wide and $\sim 30 \mathrm{~mm}$ deep crack (the portion that could be analyzed with $\mathrm{X}$-ray computed microtomography) was found to be $\sim 6 \%$ which means $94 \%$ of the crack volume was empty. Therefore, it can be said that significant strength regain through microbial induced healing was unlikely for the crack width investigated in this study $(\sim 400 \mu \mathrm{m})$. Until now there has been only one study that quantified the healed volume by calculating the total volume change of the specimen from the crack occurrence to the end of certain treatment duration (Wang et al., 2014a). In the reported quantification, the change in porosity was also included in the calculations. Moreover, the region of interest was larger which led to more noise and thus more error in quantified healing percentages. Furthermore, the accuracy was not enough to distinguish the reported $0.21 \%$ autogenous healing from the noise/error. However, in our study, we extracted the crack as the main region of interest. The accuracy of the image processing applied in our study was 

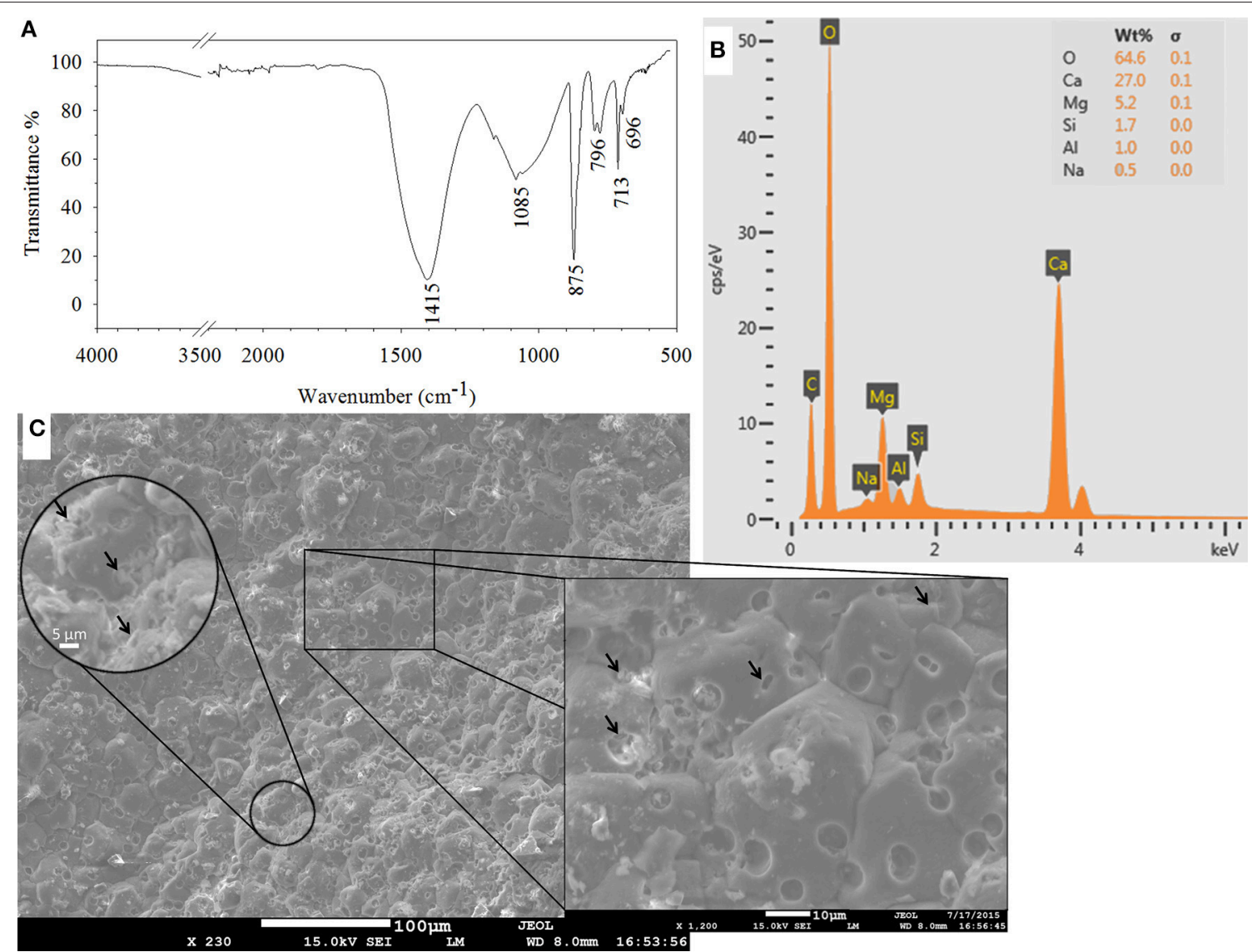

FIGURE 7 | Characterization of the healing material as calcium carbonate in FTIR spectrum of the scraped material from the inner crack surface (A); in EDS analysis (B); and in SEM micrographs of the inner crack surface of the healed biomortar (C). Arrows indicate either clusters of bacteria or traces of a single bacterium on precipitated calcium carbonate.

determined as $0.05 \%$ which was one quarter of the error reported when total volume processing was used. Since the reported volume healing by Wang et al. (2014a) was with respect to the total volume of the specimen, adequate comparison of the healed volume percentages with the reported study was not possible.

The current study also made use of a novel permeability test which has not been applied in for microbial self-healing under tap water treatment. Palin et al. (2017) applied the same permeability test to quantify microbial self-healing under low temperature marine conditions (at $8^{\circ} \mathrm{C}$ and sea water immersion). Due to the different environmental conditions during the treatment of the specimens adequate comparison of the results was not possible.

\section{CONCLUSION}

Self-healing performance of a novel biomortar containing non-axenic nitrate reducing biogranules was quantified in terms of visual crack closure, healed volume fraction with respect to the total crack volume and water tightness regain. Positive findings made investigated non-axenic biogranules a promising contender to previously proposed healing agents.

- In 28 days, microbes in ACDC containing biomortar were able to heal a $400 \mu \mathrm{m}$ crack by $95 \%$ which leads to $80 \%$ decrease in the water permeability through the crack under 0.1 bar pressure.

- The thickness of the mineral layer formed during microbial induced healing through nitrate reduction can be up to $10 \mathrm{~mm}$ along the crack depth.

- ACDC biogranules were active at the deeper parts of the crack and induced a gradation in the thickness of the crack sealing material which is distinctive when compared to autogenous healing that occurs only at the crack mouth.

- ACDC containing biomortar were able to heal $6 \%$ of the crack volume of a $400 \mu \mathrm{m}$ wide, $\sim 30 \mathrm{~mm}$ long and $30 \mathrm{~mm}$ deep crack.

Further research should be conducted to standardize and optimize the constituents of the biogranules and explore possible exploitation of microbial synergies for cost-efficient healing agent production. 


\section{AUTHOR CONTRIBUTIONS}

YE, DP, HJ, NB, and ND participated in design of the experiments, discussions of the research and interpretation of the results. DP designed the permeability tests and took part in specimen preparation for X-ray computed microtomography. SY and KT carried out the image analyses for determination of the healed volume and the sealing layer thickness. YE carried out all of the experiments, organized the analyses, combined all the information and wrote the manuscript. DP, HJ, NB, and

\section{REFERENCES}

Alazhari, M., Sharma, T., Heath, A., Cooper, R., and Paine, K. (2018). Application of expanded perlite encapsulated bacteria and growth media for self-healing concrete. Constr. Build Mater. 160, 610-619. doi: 10.1016/j.conbuildmat.2017.11.086

de Rooij, M., Van Tittelboom, K., De Belie, N., and Schlangen, E. (2013). "Self-healing phenomena in cement-based materials," in State-of-the-Art Report of RILEM Technical Committee 221-SHC, eds M. De Rooij, K. Tittelboom, N. De Belie, and E. Schlangen (Netherlands:Springer). doi: 10.1007/978-94-007-6624-2

Erşan, Y. Ç., Gruyaert, E., Louis, G., Lors, C., De Belie, N., and Boon, N. (2015a). Self-protected nitrate reducing culture for intrinsic repair of concrete cracks. Front. Microbiol. 6:1228. doi: 10.3389/fmicb.2015.01228

Erşan, Y. Ç., Hernandez-Sanabria, E., De Belie, N., and Boon, N. (2016a). Enhanced crack healing performance of microbial concrete through nitrate reduction. Cem. Concr. Compos. 70, 159-170. doi: 10.1016/j.cemconcomp.2016.04.001

Erşan, Y. Ç., Silva, F. B., Boon, N., Verstraete, W., and De Belie, N. (2015b). Screening of bacteria and concrete compatible protection materials. Constr. Build Mater. 88, 196-203. doi: 10.1016/j.conbuildmat.2015.04.027

Erşan, Y. Ç., Verbruggen, H., De Graeve, I., Verstraete, W., De Belie, N., and Boon, N. (2016b). Nitrate reducing CaCO3 precipitating bacteria survive in mortar and inhibit steel corrosion. Cem. Concr. Res. 83, 19-30. doi: 10.1016/j.cemconres.2016.01.009

Palin, D., Mo, Y., Wiktor, V., and Jonkers, H. M. (2018). An improved test for generating rapid, accurate, and reliable crack permeability data for cementitious materials. Int. J. Civ. Eng. 17, 1-8. doi: 10.1007/s40999-018-0326-8

Palin, D., Wiktor, V., and Jonkers, H. M. (2017). A bacteria-based selfhealing cementitious composite for application in low-temperature marine environments. Biomimetics 2:13. doi: 10.3390/biomimetics2030013

Silva, F., Boon, N., De Belie, N., and Verstraete, W. (2015a). Industrial application of biological self-healing concrete: challenges and economical feasibility. $J$. Commer. Biotechnol. 21, 31-38. doi: 10.5912/jcb662

Silva, F., De Belie, N., Boon, N., and Verstraete, W. (2015b). Production of nonaxenic ureolytic spores for self-healing concrete applications. Constr. Build Mater. 93, 1034-1041. doi: 10.1016/j.conbuildmat.2015.05.049

Silva, F. B. (2015). Up-scaling the production of bacteria for self-healing concrete application. Ph.D. thesis, Ghent University.
ND further improved the quality of the manuscript by their suggestions and corrections.

\section{ACKNOWLEDGMENTS}

The authors wish to thank Arjan Thijssen for his guidance during the acquisition of the $\mathrm{X}$-ray computed $\mu \mathrm{CT}$ images. The research leading to these results has been funded through the European Union Seventh Framework Programme (FP7/2007-2013) under grant agreement no 290308-SheMat.

Stuckrath, C., Serpell, R., Valenzuela, L. M., and Lopez, M. (2014). Quantification of chemical and biological calcium carbonate precipitation: performance of self-healing in reinforced mortar containing chemical admixtures. Cem. Concr. Compos. 50, 10-15. doi: 10.1016/j.cemconcomp.2014. 02.005

Tziviloglou, E., Wiktor, V., Jonkers, H. M., and Schlangen, E. (2016). Bacteria-based self-healing concrete to increase liquid tightness of cracks. Constr. Build Mater. 122, 118-125. doi: 10.1016/j.conbuildmat.2016. 06.080

Van Belleghem, B., Van den Heede, P., Van Tittelboom, K., and De Belie, N. D. (2017). Quantification of the service life extension and environmental benefit of Chloride Exposed Self-Healing Concrete. Materials (Basel) 10:5. doi: $10.3390 / \mathrm{ma} 10010005$

Wang, J., Dewanckele, J., Cnudde, V., Van Vlierberghe, S., Verstraete, W., and De Belie, N. (2014a). X-ray computed tomography proof of bacterial-based self-healing in concrete. Cem. Concr. Compos. 53, 289-304. doi: 10.1016/j.cemconcomp.2014.07.014

Wang, J., Soens, H., Verstraete, W., and De Belie, N. (2014b). Self-healing concrete by use of microencapsulated bacterial spores. Cem. Concr. Res. 56, 139-152. doi: 10.1016/j.cemconres.2013.11.009

Wiktor, V., and Jonkers, H. M. (2011). Quantification of crack-healing in novel bacteria-based self-healing concrete. Cem. Concr. Compos. 33, 763-770. doi: 10.1016/j.cemconcomp.2011.03.012

Zhang, J., Liu, Y., Feng, T., Zhou, M., Zhao, L., Zhou, A., et al. (2017). Immobilizing bacteria in expanded perlite for the crack self-healing in concrete. Constr. Build Mater. 148, 610-617. doi: 10.1016/j.conbuildmat.2017.05.021

Conflict of Interest Statement: The authors declare that the research was conducted in the absence of any commercial or financial relationships that could be construed as a potential conflict of interest.

Copyright (c) 2018 Ersan, Palin, Yengec Tasdemir, Tasdemir, Jonkers, Boon and De Belie. This is an open-access article distributed under the terms of the Creative Commons Attribution License (CC BY). The use, distribution or reproduction in other forums is permitted, provided the original author(s) and the copyright owner(s) are credited and that the original publication in this journal is cited, in accordance with accepted academic practice. No use, distribution or reproduction is permitted which does not comply with these terms. 